Rogers, H. J. (1957). J. gen. Microbiol. 16, 22-37

\title{
The Preferential Suppression of Hyaluronidase Formation in Cultures of Staphylococcus aureus
}

\author{
BY H. J. ROGERS \\ National Institute for Medical Research, Mill Hill, London, N.W. శ
}

SUMMARY: When Staphylococcus aureus strain 524/SC/55 is inoculated from an overnight culture into fresh broth only small amounts of hyaluronidase are formed at first, but while growth proceeds at a constant exponential rate an increasing proportion of the cell protein is secreted into the medium as hyaluronidase. This increase in proportion continues for eleven generations. Thereafter, it remains constant even when the organisms are transferred to fresh medium. The organisms of the inoculum taken from overnight cultures are deficient in thiamine and a partial deficiency of this and other essential growth factors suppresses the proportion of hyaluronidase formed. The accumulation of $\alpha$-aminobutyric acid in organisms from overnight cultures was demonstrated; the addition of this substance to cultures decreases the proportion of cell protein which is turned into hyaluronidase.

It was shown (Rogers, 1954) that when staphylococci grew exponentially in broth or in casein hydrolysate media, the appearance of hyaluronidase activity in the cultures at first lagged and then accelerated throughout the period of rapid growth, leading to a continuously increasing ratio of enzymic activity to mass of organisms. Attempts were made to exclude activation of pro-enzyme, inactivation of enzyme formed early in the cultures or delayed secretion, as explanations of the phenomenon. If it be accepted that the measured hyaluronidase activities represent the amount of enzyme formed, then the increase in ratio of hyaluronidase activity to mass of bacteria during growth of a culture shows that an increasing proportion of the cell protein is secreted into the culture fluid as enzyme. If rapid growth could be extended for a longer period than normally occurs in a shaken flask culture, it seems that this increase must sooner or later cease and the ratio of hyaluronidase activity to total mass of bacterial protein become constant, i.e. the amount of enzyme formed must eventually be a constant proportion of the growing organism. In the present work, staphylococci were allowed to grow rapidly in broth for periods of up to $24 \mathrm{hr}$. in a continuous culture apparatus. During this period the ratio of hyaluronidase activity to mass of growth at first increased and then, as expected, became constant. When the cocci from such cultures were then transferred to fresh medium, hyaluronidase continued to form a constant proportion of the cell-mass during growth.

In all the work to be described the inoculum was taken from overnight cultures in which rapid growth had ceased for some time. It has now been found that cocci from such cultures are deficient in thiamine and that partial thiamine deficiency can decrease the proportion of hyaluronidase which is formed. It is suggested that this thiamine deficiency, together possibly with the accumulation of an inhibitor in the inoculum, might indirectly explain the slow acceleration to a steady rate of hyaluronidase formation. 


\section{METHODS}

\section{Organisms}

The strain of Staphylococcus aureus originally isolated by selection of a single coccus from strain 524 (Rogers, 1953) and called 524/SC/55 was studied exclusively. At about 4-monthly intervals a broth culture of the organism was seeded on nutrient agar and after incubation the resulting growth was harvested and again dried in ampoules by the Stamp (1947) technique. The overnight cultures for inoculation of the experiments recorded in the present paper were prepared by suspending the contents of one such ampoule in the required volume of broth in a conical flask which was shaken at $\mathbf{3 5}^{\circ}$.

Media. Wright broth (Wright, 1933) was preferred to casein hydrolysate or more chemically defined media since staphylococcal hyaluronidase was stable during incubation for periods of at least $6 \mathrm{hr}$. in this medium. Some destruction occurred when casein hydrolysate dilutions of hyaluronidase were similarly treated. The broth was sometimes buffered by the aseptic addition of sufficient sterile $50 \%(\mathrm{w} / \mathrm{v})$ solution of sodium $\beta$-glycerophosphate to give a final concentration of $2.5 \%$. The final glucose concentration of the media was increased to $0.25 \%$ by the aseptic addition of $10 \%$ glucose solution previously sterilized by autoclaving at $120^{\circ}$ for $15 \mathrm{~min}$.

\section{Procedure for flask cultures}

Sterile, conical flasks, of different sizes from $50 \mathrm{ml}$. to $1 \cdot 0 \mathrm{l}$. and plugged with cotton wool, were one-fifth filled with medium. The medium was then inoculated with $0.15 \mathrm{ml} . / 100 \mathrm{ml}$. of an overnight culture of organism; such an inoculum gave $c .10^{6} \mathrm{cocci} / \mathrm{ml}$. The inoculated flasks were shaken at the maximum throw of a shaker (Kantorowicz, 1951) at $35^{\circ}$. Subsequent work has shown that such a procedure did not result in equal availability of oxygen to solutions in the different sizes of flask, but that in some aeration was poorer

Table 1. Oxygen availability determined by the rate of oxidation of $0.5 \mathrm{~N}-$ sodium sulphite containing $10^{-4} \mathrm{M}_{-} \mathrm{CuSO}_{4}$ at $35^{\circ}$

The flasks were shaken at the maximum throw of the shaker. Samples $(2 \mathrm{ml}$.) were taken into $2.0 \mathrm{ml}$. of $0.5 \mathrm{~N}$-iodine. The residual iodine was determined by titration with $0.1 \mathrm{~N}$-sodium thiosulphate.

$\begin{array}{cccc}\begin{array}{c}\text { Flask } \\ \text { vol. }\end{array} & \begin{array}{c}\text { Fluid } \\ \text { vol. } \\ (\mathrm{ml})\end{array} & \begin{array}{c}\text { Oxygen } \\ \text { solution }\end{array} & \\ 50 & (\mathrm{ml}) & (\mathrm{ml} . / \mathrm{hr} . / 100 \mathrm{ml} .) & \mathbf{K}_{\mathrm{L}} \mathrm{a}^{*} \\ 100 & 10 & 53 & 140 \\ 250 & 20 & 53 & 140 \\ 1000 & 50 & 30 & 81 \\ & 200 & 65 & 171\end{array}$

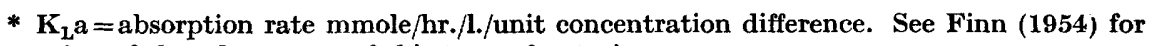
discussion of the advantages of this type of notation.

than in others. The availability of oxygen was measured by the rate of oxidation of $0.5 \mathrm{~N}$-sulphite solution catalysed by $10^{-4} \mathrm{M}-\mathrm{CuSO}_{4}$. Table 1 shows the results obtained by this method when applied to fluid of four flasks of 
increasing size, each filled with one-fifth of its volume of $0.5 \mathrm{~N}-\mathrm{Na}_{2} \mathrm{SO}_{3}$ and shaken under the same conditions as the cultures. Aeration was least good for $50 \mathrm{ml}$. in a $250 \mathrm{ml}$. flask and best for $200 \mathrm{ml}$. in a litre flask. It seems likely that the difference can be explained as a result of different ratios of surface to fluid volume in the flasks and to the degree of turbulence caused by shaking. The ratio was greatest for the smallest flask and the turbulence greatest for the largest. The differences in the degree of oxygen availability did not seem to affect the behaviour of the cocci in the experiments to be reported here, since the same results for growth and hyaluronidase formation were obtained in different-sized flasks. Calculations of the oxygen consumption by the organisms from the $Q_{\mathrm{O}_{2}}\left(\mu 1 . \mathrm{O}_{2}\right.$ absorbed $/ \mathrm{hr} . / \mathrm{mg}$. dry wt.), determined whilst the organisms were growing in broth, showed that oxygen supply would not become limiting, even in the most unfavourable sizes of flask, until the region in which hyaluronidase formation ceased. The rates of hyaluronidase formation and growth were mostly measured at bacterial densities of about 20-50\% of that at which oxygen supply became limiting, and were thus not likely to be influenced by oxygen shortage.

\section{Procedure for continuous culture}

The continuous culture apparatus was similar to the 'bactogène' described by Monod (1950) and was totally enclosed in a warm room at $35^{\circ} \pm 0 \cdot 2^{\circ}$. The supply of medium was fed by gravity into a constant head device (Marriotte bottle) and from this again by gravity through $15 \mathrm{ft}$. of $1.5 \mathrm{~mm}$. diameter capillary glass tubing into an enclosed dripper of wide ( $>2 \mathrm{~mm}$.) nozzle diameter. From the dripper the medium flowed into a revolving (200 r.p.m.) flask ( 5 in. diam.) containing $100 \mathrm{ml}$. medium. The volume of the culture was maintained constant by a suction tube bent to touch the surface of fluid within the flask. The rate of flow of the medium was varied by altering the vertical distance between the nozzle of the dripper and the level in the Marriotte bottle, and was measured by counting the number of drops/min. Warm, wet, sterile air was pumped (31./min.) over the surface of the culture. The method of medium feed was selected for the rapid flow rates of the present work, from the many pumping and other possible methods, as the simplest, most controllable and least liable to variation. It is important that the capillary should be long and wide rather than short and narrow, in order to avoid blocking by fibres of cotton wool or other particulate material in the medium. Measurements of the oxygen solution rates by the sulphite oxidation method showed that a bacterial population equivalent to $1.5 \mathrm{mg}$. dry wt. bacteria/ml. grew without the oxygen demand exceeding the solution rate. The greatest densities of organisms used in the present work were equivalent to about $1.0 \mathrm{mg}$. dry wt./ml.; most of the experiments were at densities of about 0.3-0.5 mg. dry wt./ml. To study hyaluronidase formation during the rapid growth of staphylococci the apparatus was run so that the growth rate was 'internally controlled' (Novick, 1955). To do this $100 \mathrm{ml}$. medium in the flask of the apparatus were inoculated with $0.15 \mathrm{ml}$. of an overnight culture, the flask revolved and the air supply started. The medium flow was not turned 
on until the culture had reached the required density as judged by optical opacity measurements. The flow of medium was then started and increased until the population density fell slightly; then by slightly decreasing the flow rate again a constant opacity could be maintained. Since any increase in the rate of flow of the medium tended to wash-out organisms the rate of division was maximal for the medium.

The operation of the bactogène as an internally compensated system without photoelectric devices to monitor the opacity of the culture obviously requires more care than for slow growth of organisms with a known limiting factor. Moreover, it is probably unsafe to regard the conditions in the continuous culture of staphylococci growing on complex media at minimum generation times as reaching a steady state during the experiments. Considerable fluctuation in the concentration of nutrients may be possible. If such fluctuations occurred, however, they did not affect the growth rate. Once the correct rate of flow of medium had been established, no further adjustments were necessary. In view of our inadequate knowledge of the biosynthetic processes necessary to form proteins and other complex molecules, it may be wiser to regard the steady state in cells as a condition reached for the concentration of all components of the cell in an infinite number of generations but not necessarily in existence after any finite number.

During continuous culture experiments, samples of $\mathbf{2 - 5} \mathrm{ml}$. were withdrawn aseptically at intervals through a sampling tube provided on the apparatus, cooled rapidly to $0-4^{\circ}$, measured for optical opacity and centrifuged in the cold. The supernatant fluids were then removed and stored at $0-4^{\circ}$ under toluene for not more than $\mathbf{2 4} \mathrm{hr}$. before their hyaluronidase potency was assayed.

\section{Analytical methods}

Growth and hyaluronidase. These were estimated as previously described (Rogers, 1954). The results are expressed as $\mathrm{mg}$. bacterial nitrogen $/ \mathrm{ml}$. and Turbidity Reducing Units (TRU)/ml. respectively.

Thiamine was assayed by the yeast fermentation method (Atkin, Schultz \& Frey, 1939; modified by Kline \& Friedman, 1947). The method was further modified for the conventional Warburg apparatus. Casein hydrolysate, pyridoxin, nicotinamide and salts were present as well as glucose in the suspension medium for the yeast. The manometers were gassed with argon for $1 \mathrm{hr}$. before starting the manometric readings. It was found to be important to dilute the standard thiamine solutions in $\mathbf{0 . 2} \%$ gelatin (as suggested by Kline \& Friedman, 1947) rather than in water, if consistent results were to be obtained. A straight line response was obtained for concentrations between 5 and $30 \times 10^{-9} \mathrm{~g}$. thiamine.

\section{RESULTS}

Fig. 1 shows the type of results obtained in the continuous culture experiments. In this particular experiment, the density of the culture was held constant at about $0.04 \mathrm{mg}$. bacterial $-\mathrm{N} / \mathrm{ml}$. and the mean generation time was $37 \mathrm{~min}$. The hyaluronidase activity $/ \mathrm{ml}$. culture increased from about $2 \cdot 0 \mathrm{TRU} / \mathrm{ml}$. to 
$25 \mathrm{TRU} / \mathrm{ml}$. during the first $2-3 \mathrm{hr}$. of the experiment. Since the population density of the culture was maintained approximately constant during this time, the increase in enzyme activity/ml. culture means that there was a corresponding increase in the amount of hyaluronidase formed/mg. new bacterial protein formed. Hence the proportion of the bacterial protein secreted into the medium as hyaluronidase, starting very low, increased as the run continued and finally became constant at a relatively high value, as indicated by the part of the enzyme curve in Fig. 1 which is parallel to the time

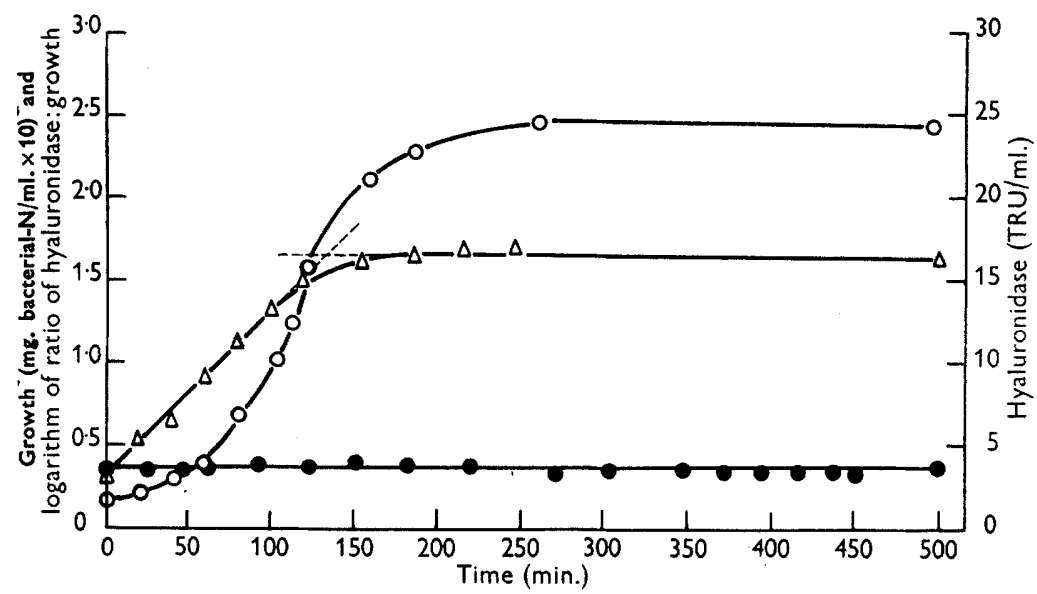

Fig. 1. The formation of hyaluronidase during a continuous culture experiment. $\quad=$ bacterial density (mg. bacterial-N/ml., $\times 10$ ). $O=$ hyaluronidase activity (TRU/ml.). $\Delta=$ logarithm of the ratio hyaluronidase activity : mass of bacterial-N.

axis. Results similar to those shown in Fig. 1 were obtained in eighteen different continuous culture experiments. When the density of the culture was maintained at low values, the increase in proportion of hyaluronidase formed was usually greater, owing to the lower starting value, than at higher values (see Table 2). In three experiments, no increase in hyaluronidase occurred. These three experiments coincided with an attempt to replace the glass capillary tube on the medium feed of the apparatus by rubber tubing. It appeared that after two complete experiments during which the whole apparatus would be sterilized twice by autoclaving, the rubber tubing altered the medium in such a way that although the growth rate was as expected, no hyaluronidase was formed. The nature of the change brought about by rubber tubing has not been investigated.

Calculations were made of the total number of generations between inoculation and the point at which the organisms reached a steady rate of hyaluronidase formation (i.e. the point at which the enzyme formed a constant proportion of the bacterial protein of the growing cocci. This number of generations is made up of those which occur between inoculation and switching in the medium feed of the apparatus, and those which occur at constant bacterial density in the continuous culture. The curve for hyaluronidase potency does not flatten 
abruptly, and some point had to be fixed arbitrarily in order to make the calculations. The time chosen was that of an intersection of the extrapolation of the logarithmic plot of the ratio of hyaluronidase activity: mass of growth during the first $2 \mathrm{hr}$. which was an approximately straight line, with the horizontal line for the steady value of the ratio finally achieved. This method of deriving the point is indicated by broken lines in Fig. 1. Table 2 shows the results of the calculations, obtained from six different experiments. Within

\section{Table 2. The number of generations required before hyaluronidase formation and growth proceed at the same exponential rate}

The organisms were grown at constant densities of organisms (M) until after the exponential rates of enzyme formation and growth became equal at time (T). The number of generations between the original inoculation of the culture with $7 \times 10^{-4} \mathrm{mg}$. bacterial- $\mathrm{N} / \mathrm{ml}$. and time (T) was calculated.

\begin{tabular}{|c|c|c|c|c|c|c|}
\hline \multirow[b]{2}{*}{ Expt. } & \multirow{2}{*}{$\begin{array}{c}\mathbf{M} \\
\text { (mg. bacterial- } \\
\mathrm{N} / \mathrm{ml} \text {.) }\end{array}$} & \multirow{2}{*}{$\underset{\text { (min.) }}{\mathbf{T}}$} & \multirow{2}{*}{$\begin{array}{c}\text { m.g.t.* } \\
\text { (min.) }\end{array}$} & \multirow[b]{2}{*}{ Generations } & \multicolumn{2}{|c|}{ Enzyme $(E / G) \dagger$} \\
\hline & & & & & Initial & Final \\
\hline 1 & 0.100 & 145 & 40 & $10 \cdot 7$ & 410 & 940 \\
\hline 2 & 0.072 & 167 & 24 & $13 \cdot 7$ & $\mathbf{8 3}$ & 840 \\
\hline 3 & 0.050 & 137 & 28 & $11 \cdot 1$ & 199 & 970 \\
\hline 4 & 0.050 & 140 & 33 & $10 \cdot 8$ & 24 & 520 \\
\hline 5 & $0 \cdot 040$ & 112 & 21 & $10 \cdot 9$ & 117 & 710 \\
\hline 6 & 0.035 & 195 & 37 & $10 \cdot 8$ & $\mathbf{3 6}$ & 700 \\
\hline
\end{tabular}

* Mean generation time.

$\dagger$ Ratio of hyaluronidase (in TRU/ml.) to mass of bacterial growth as mg. bacterial- $\mathbf{N} / \mathbf{m}$

very close limits five out of six of the experiments showed that a total of eleven generations had to elapse before the exponential rates of hyaluronidase formation and growth became equal (i.e. before hyaluronidase protein formed a constant proportion of the total). The considerable variation in the mean generation times of the organisms in the different experiments was caused by uncontrolled differences between different batches of broth. The one experiment in which a value different from eleven generations was obtained (Expt. 2) was unsatisfactory because an electrical failure stopped the apparatus for some time, and during further adjustments the bacterial density doubled. It seems likely that this may account for the difference between Expt. 2 and the others.

\section{Re-growth of cocci from a continuous culture}

The establishment of a steady rate of hyaluronidase formation which occurred eleven generations after inoculation of medium with cocci from an overnight culture might be due to a change in the fluid part of the culture or to a change in the organisms. If the latter had occurred, the organisms should continue to grow in a fresh medium with a constant ratio of hyaluronidase activity to mass of growth. To test this possibility, cocci introduced into fresh broth from a continuous culture which had been running for 6-7 hr. (equivalent to seventeen generations from inoculation) were compared with respect to growth and hyaluronidase formation with the behaviour of cocci taken from a shaken flask culture of the same opacity which had been inoculated in the 
same way as the continuous culture but in which only four to five generations of growth had occurred. The details of the experiment were as follows. The continuous culture was maintained at an opacity equivalent to $0.036 \mathrm{mg}$. bacterial- $\mathrm{N} / \mathrm{ml}$. for $6 \mathrm{hr}$.; hyaluronidase determinations showed that the curve had flattened after the usual eleven generations (i.e. after $3 \mathrm{hr} .30 \mathrm{~min}$. growth). The culture was cooled in ice water and $25 \mathrm{ml}$. of it centrifuged at $0-4^{\circ}$. At the same time as the medium flow of the continuous culture apparatus was started, a $500 \mathrm{ml}$. conical flask containing $100 \mathrm{ml}$. of warmed broth was inoculated with $0.15 \mathrm{ml}$. of the same overnight culture as used for the continuous culture. This flask was shaken until the opacity was equivalent to $0.036 \mathrm{mg}$. bacterial-s/ $/ \mathrm{ml}$. and then cooled. A sample (25 ml.) of this culture was also centrifuged in the cold. The two sets of cocci were then suspended, without washing, in $100 \mathrm{ml}$. of warmed broth in $500 \mathrm{ml}$. flasks, returned to the incubator and shaken. Samples $(2.5 \mathrm{ml}$.) were removed initially and at $20 \mathrm{~min}$. intervals during $3 \mathrm{hr}$; the mass of growth and the hyaluronidase activities were estimated in the samples.

Difficulties were encountered in finding the most satisfactory way of analysing the results obtained. When the results for growth from a large inoculum and for the formation of any extracellular enzyme liberated into a fresh enzyme-free medium, are plotted logarithmically against time, they do not give parallel straight lines, even though a constant proportion of cellmaterial is liberated as enzyme. The device employed by Monod, Pappenheimer \& Cohen-Bazire (1952), however, of plotting increase in enzyme activity/ml. culture $[\Delta E]$ against increase in mass of growth $[\Delta G]$ overcomes this difficulty and has proved satisfactory. When a constant proportion of the cell protein synthesized is turned into hyaluronidase, a straight line will result. When enzyme formation accelerates relative to growth, a curve convex to the increase in mass axis is obtained. Fig. 2 shows three comparisons of the behaviour of continuous culture organisms (Fig. $2 a$ ) with that of rapidlygrowing shaken flask culture organisms (Fig. 2b). The continuous culture organisms formed a constant proportion of hyaluronidase (i.e. the ratio of hyaluronidase activity/mass of growth remained constant) and the plots of $\Delta G$ against $\Delta E$ are straight lines. The flask-grown organisms gave the expected convex curve, showing that the ratio hyaluronidase activity: mass of growth had increased. The cause of the considerable differences in the slopes of the straight lines obtained from the continuous culture organisms in different experiments is unknown. Similar results were obtained in two other experiments.

No sodium $\beta$-glycerophosphate was included in the media for the above experiments. Inclusion of this buffer in the continuous culture medium had no influence on the qualitative or quantitative aspects of hyaluronidase formation. When glycerophosphate was added to the media for re-growth of organisms in flask cultures, a slightly convex curve was obtained for the increasing growth: enzyme formation plot. The curvature was, however, very slight when compared with the results in Fig. $2 b$. It was now important to know how rapidly organisms which had divided eleven times reverted to organisms 
which behaved like those from an ordinary overnight culture and which, when re-suspended in fresh medium, formed an increasing proportion of hyaluronidase during growth. A culture was grown for twelve generations in the continuous culture apparatus at a density of $0.05 \mathrm{mg}$. bacterial- $\mathrm{N} / \mathrm{ml}$. A volume $(10 \mathrm{ml}$.) was then removed aseptically and placed in a $50 \mathrm{ml}$. conical flask and shaken at $35^{\circ}$ for $14 \mathrm{hr}$. The density at the end of this

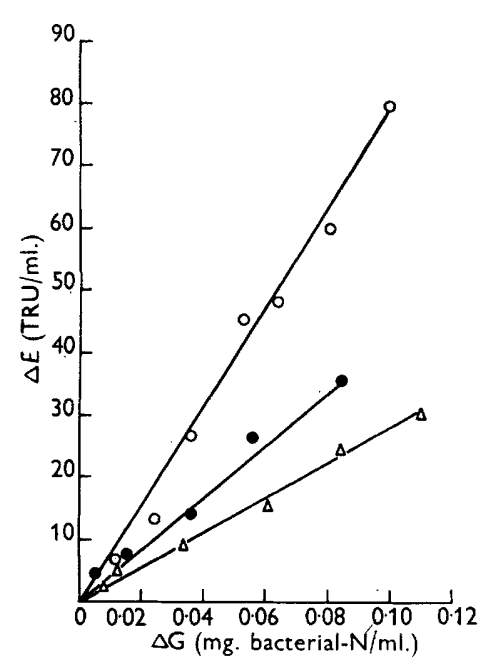

a

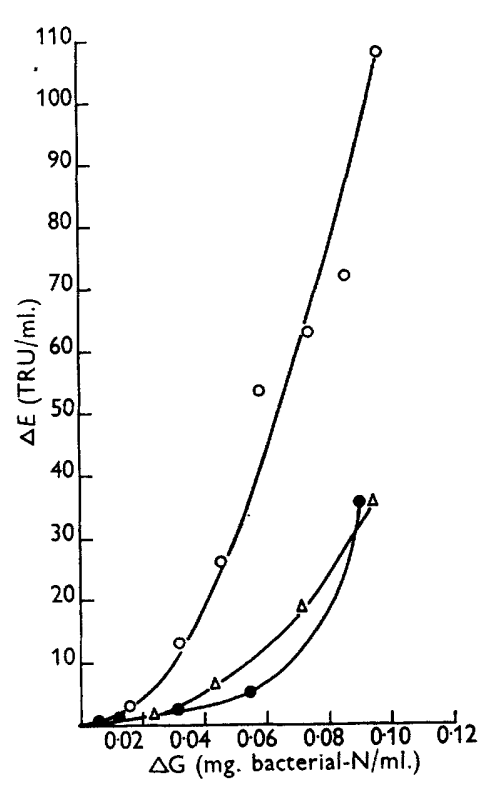

$\boldsymbol{b}$

Fig. 2. Plot of the increase in growth (in $\mathrm{mg}$. bacterial-N/ml., $\Delta G$; against increase in hyaluronidase (TRU/ml.), $\Delta \boldsymbol{E}$. Cultures grown in shaken flask cultures at $35^{\circ} .0$, and $\Delta$ represent the results from three separate experiments. (a) Inoculum from a continuous culture. (b) Inoculum from a shaken flask culture.

incubation period was $0.6 \mathrm{mg}$. bacterial-N/ml. The cocci were separated by centrifugation and re-suspended in fresh medium containing no glycerophosphate to a density equivalent to $0.005 \mathrm{mg}$. bacterial-N/ml. Samples were taken at regular intervals and growth and hyaluronidase potency estimated as usual. Fig. 3 shows that the plot of the increase in mass of growth against hyaluronidase activity was again markedly convex, indicating that the cocci from the continuous culture had already reverted to the type of organisms present in an overnight culture during the four to five divisions during the incubation of the continuous culture cocci in a shaken flask. During these few generations, the growth rate gradually declined and almost ceased.

\section{Selective suppression of hyaluronidase formation}

The above findings suggested that the change during incubation of a culture overnight had affected the organisms in such a way that the general processes of protein formation necessary for growth and those for hyaluronidase 
formation occurred at different rates when the cocci were inoculated into fresh medium. The rate of change of the organisms in both directions argues against a selection of mutants with differing ability to form hyaluronidase and in favour of some change in the majority of the population in the culture. Previously it was shown (Rogers, 1954) that during the late period of slow growth in an overnight culture no more hyaluronidase was formed. It now seems reasonable to argue that the cocci become progressively deficient in some substance during this period of growth.

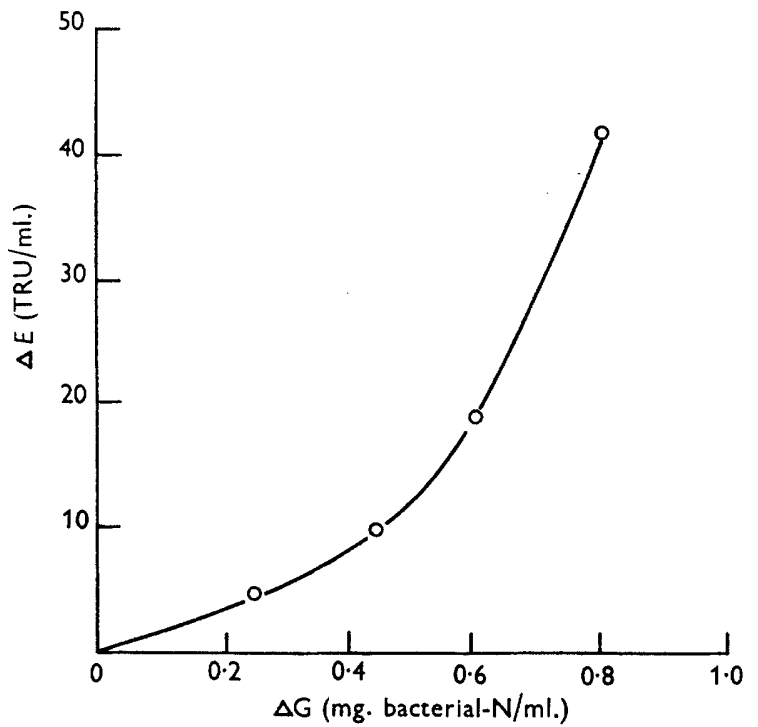

Fig. 3. Plot of the increase in growth (in $\mathrm{mg}$. bacterial- $\mathrm{N} / \mathrm{ml}$.), $\Delta G$ against increase in hyaluronidase (in TRU/ml.), $\Delta E$ for a culture inoculated with cocci from a continuous culture which was removed from the apparatus and shaken overnight in a flask at $35^{\circ}$.

\section{Thiamine deficiency}

Early in the work it was found that the supernatant fluid obtained from a 'young shaken culture' in which the cocci were dividing rapidly would support growth of cocci from an overnight shaken culture, but that very little more hyaluronidase was usually formed. The details of an experiment demonstrating this are as follows. Two volumes $(200 \mathrm{ml}$.) of broth supplemented with lycerophosphate, warmed to $35^{\circ}$ and contained in 1 l. plugged conical flasks, were each inoculated with $0.3 \mathrm{ml}$. of an overnight culture. The flasks were incubated with shaking until the optical opacity of one of the cultures (A) was equivalent to $0.023 \mathrm{mg}$. bacterial- $\mathrm{N} / \mathrm{ml}$. This culture (A) was then cooled to $5^{\circ}$ and centrifuged in the cold. The supernatant fluid was removed aseptically and stored at $-2^{\circ}$. The second flask (culture B) was incubated overnight, then centrifuged and the organisms, drained of supernatant fluid, were re-suspended in $100 \mathrm{ml}$. fresh cold broth. Volumes $(20 \mathrm{ml}$.) of the supernatant fluid from (A) were then pipetted into four $100 \mathrm{ml}$. plugged conical flasks and warmed to $35^{\circ}$. To two of these flasks $0.2 \mathrm{ml}$. of sterile glucose solution, $10 \% \mathrm{w} / \mathrm{v}$, was added. 
A third pair of flasks contained fresh broth supplemented with glycerophosphate and warmed to $35^{\circ}$. All the flasks were inoculated with sufficient of the suspension of cocci from (B) to give a density equivalent to 0.015-0.02 $\mathrm{mg}$. bacterial-N/ml. They were incubated with shaking for $5.5 \mathrm{hr}$., i.e. until hyaluronidase formation had ceased. The cultures were then cooled to $0-5^{\circ}$, their optical opacities measured, and then centrifuged. Hyaluronidase was measured in the supernatant fluids; Table 3 shows the results obtained. The increase in mass of organism in the supernatant fluid was about $40 \%$ less than

\section{Table 3. Preferential suppression of hyaluronidase formation due to depletion of the medium}

The supernatant fluid (A) was obtained from a culture of Staphylococcus aureus growing logarithmically in broth medium and which had reached a density equivalent to $0.02 \mathrm{mg}$. bacterial- $\mathrm{N} / \mathrm{ml}$. The inoculum contained sufficient cocci from a culture incubated $18 \mathrm{hr}$. to give an initial density of $0.015-0.02 \mathrm{mg}$. bacterial-N/ml. The flasks $(100 \mathrm{ml}$. conical flasks containing $20 \mathrm{ml}$. of fluid) were incubated with shaking for $5.5 \mathrm{hr}$. at $35^{\circ}$.

\begin{tabular}{lccc}
\multicolumn{1}{c}{ Medium } & $\Delta G^{*}$ & $\Delta E \dagger$ & $\Delta E / \Delta G$ \\
Supernatant fluid A & $0 \cdot 133$ & $6 \cdot 3$ & 47 \\
Supernatant fluid A +glucose $(0 \cdot 1 \%)$ & $0 \cdot 132$ & $\mathbf{7 \cdot 9}$ & 60 \\
Fresh broth & $\mathbf{0 \cdot 2 1 3}$ & $\mathbf{1 7 1}$ & $\mathbf{8 1 0}$ \\
& * Increase in mass of growth in mg. bacterial-N/ml. \\
& + Increase in hyaluronidase in TRU/ml.
\end{tabular}

that obtained in fresh broth, but hyaluronidase formation was decreased by $97 \%$. The addition of more glucose to the supernatant fluid had no significant effect. Nine different batches of broth were examined by the above technique; with one exception similar results were obtained. With five out of nine batches growth was $20-40 \%$ less in the supernatant fluid than in fresh broth but hyaluronidase was more than $70 \%$ less. In two batches growth was only 7-10\% less, whereas hyaluronidase formation was 80 and $90 \%$ less. It seemed that the supernatant fluid from a 'young culture' was already partially deficient in some material necessary for growth and enzyme formation and that this deficiency selectively suppressed hyaluronidase formation.

A variety of known growth factors was then added to supernatant fluid obtained from young shaken cultures by the above technique. Organisms from an overnight culture were added and the cultures incubated until hyaluronidase formation had ceased. The results for growth and hyaluronidase estimations are shown in Table 4. It will be seen that thiamine was capable of restoring hyaluronidase-forming capacity to the supernatant fluid. Thus cocci from an overnight culture and supernatant fluid from a young culture together had insufficient thiamine, suggesting that thiamine was concentrated from the medium by the cocci from the overnight culture during the first few divisions. The cocci can, presumably, grow and form hyaluronidase at the expense of this store.

The amounts of thiamine in the cocci and supernatant fluid in a culture were measured at various stages of growth. Five amounts $(200 \mathrm{ml}$.) of broth 
Table 4. Addition of substances to the depleted supernatant fluid

Supernatant fluid from a logarithmically growing culture was prepared when the population density was equivalent to $0.02 \mathrm{mg}$. bacterial- $\mathrm{N} / \mathrm{ml}$. This supernatant fluid was dispensed in $10 \mathrm{ml}$. amounts in $50 \mathrm{ml}$. conical flasks and supplemented by the various factors. Volumes $(0 \cdot 1 \mathrm{ml}$.) of the solutions of supplements were added to each flask. The flasks were inoculated and incubated as in Table 3.

$\quad$ Supplement
Unsupplemented
Mixed amino acids*
Growth-factor mixture $1 \dagger$
Growth-factor mixture $4 \ddagger$
Growth-factor mixture $5 \$$
Growth-factor mixture $6 \|$
1-Glutamine
Thiamine
Fresh broth

Fresh broth

\begin{tabular}{|c|c|}
\hline \multicolumn{2}{|c|}{$\Delta \boldsymbol{G}$} \\
\hline I & II \\
\hline $0 \cdot 234$ & 0.217 \\
\hline & 0.171 \\
\hline $0 \cdot 318$ & 0.277 \\
\hline 0.238 & - \\
\hline $0 \cdot 226$ & - \\
\hline 0.246 & 0.271 \\
\hline- & 0.165 \\
\hline- & 0.271 \\
\hline $0 \cdot 230$ & $0 \cdot 283$ \\
\hline
\end{tabular}

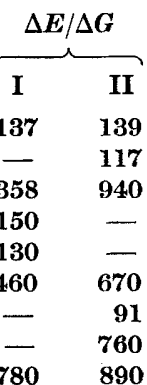

* A mixture of amino acids to imitate the composition of cow's milk casein.

$\dagger$ This mixture had the following composition: nicotinamide, $50 \mathrm{mg}$.; Ca pantothenate, $100 \mathrm{mg}$; ; pyridoxin, $50 \mathrm{mg}$; riboflavin, $5 \mathrm{mg}$.; thiamine, $50 \mathrm{mg}$.; glutamine, $100 \mathrm{mg}$. ; $p$-aminobenzoic acid, $10 \mathrm{mg}$. Dissolved in $50 \mathrm{ml}$. water and sterilized by Seitz filtration.

¥ Contained nicotinamide, pyridoxin and $p$-aminobenzoic acid as in solution 1 .

$\$$ Contained Ca pantothenate and riboflavin as in solution 1 .

if Contained thiamine and glutamine as in solution 1.

containing $2 \cdot 5 \%$ sodium $\beta$-glycerophosphate and $\mathbf{0} \cdot \mathbf{2 5} \%$ glucose, warmed at $35^{\circ}$ in 1 l. flasks, were each inoculated with $0.3 \mathrm{ml}$. of an overnight culture grown in the same medium. When growth in the individual cultures reached the values indicated in Table 5, single flasks were removed from the incubator, cooled in ice water and centrifuged. A sample of the supernatant fluid was removed and the cocci washed once with $50 \mathrm{ml}$. distilled water. The washings were retained for thiamine assays in the first experiment but were subsequently rejected since none was detected in them. The cocci were then suspended in $10 \mathrm{ml} . \mathrm{H}_{2} \mathrm{O}$, the opacity of the suspensions measured and $\mathrm{N}-\mathrm{HCl}$ added until they were acid to congo red. The suspensions and supernatant fluids (also acidified) were then heated for $30 \mathrm{~min}$. at $100^{\circ}$ to liberate thiamine (Kline \& Friedman, 1947), neutralized to $\mathrm{pH} 6.0$ with $\mathrm{N}-\mathrm{NaOH}$ and adjusted to a volume of $25 \mathrm{ml}$. In some experiments the suspensions were subsequently treated with acidified sulphite solution (Schultz, Atkin \& Frey, 1942) which alters the thiamine so that it will no longer assay by the yeast method but which leaves unaltered the free pyrimidine moiety which also, at higher concentrations, stimulates yeast and might confuse the estimations. Such experiments showed that about 75-95\% of the activity of the coccal suspensions in the yeast test was due to thiamine. In the supernatant fluids about $50 \%$ of the activity remained after sulphite treatment. Hence these latter values are much less certain. As far as could be judged, however, no alteration took place in the ratio of sulphite-destructible to sulphite-stable activity during the growth of the organisms.

Table 5 shows that the amount of thiamine/mg. bacterial-N was highest in 
the first sample in the recorded experiment. Thereafter the concentration of the growth factor in the cocci fell. A calculation of the expected concentrations of thiamine, made by assuming that all the growth which occurred after the first sample had been taken was at the expense of that stored in the cocci, shows that small amounts of thiamine continued to be removed from the fluid

\section{Table 5. The concentration of thiamine in growing cultures of Staphylococcus aureus}

Five conical flasks ( 1 l.), each containing $200 \mathrm{ml}$. medium, were incubated with shaking at $35^{\circ}$. One flask was removed, cooled and centrifuged at each of the times indicated in column 1 . The cocci were washed and the thiamine in the cocci and in the supernatant fluid estimated as described in the text.

$\begin{array}{rlccc}\begin{array}{r}\text { Time } \\ \text { (hr.; min.) }\end{array} & \begin{array}{c}\text { Growth in } \\ \text { culture (mg. } \\ \text { bacterial-N/ml. })\end{array} & \begin{array}{c}\text { Cocci } \\ (\mu \mathrm{g} . / \mathrm{mg} .\end{array} & \begin{array}{c}\text { Supernatant } \\ \text { bacterial-N })\end{array} & \begin{array}{c}\text { fluid } \\ (\mu \mathrm{g} . / \mathrm{ml} .)\end{array} \\ 3 & \mathbf{0 5} & 0 \cdot 0071 & 2 \cdot 4 & 0 \cdot 15 \\ 4 & 20 & 0 \cdot 0320 & 1 \cdot 2 & 0 \cdot 15 \\ 5 & 10 & 0 \cdot 065 & 0 \cdot 80 & 0 \cdot 14 \\ 6 & 55 & 0 \cdot 151 & 0 \cdot 41 & 0 \cdot 12 \\ 18 & 0 & 0 \cdot 310 & 0 \cdot 28 & 0 \cdot 12 \\ & & \text { Uninoculated broth } & 0 \cdot 23\end{array}$

by the organisms. After $c .7 \mathrm{hr}$. of growth, for example, the mass of bacteria in the culture had increased just over twenty times, whereas the internal thiamine concentration had decreased only six times. The probability of a continued uptake of thiamine by the cocci is supported by the decrease in the external thiamine concentration. Rather more disappeared from the fluid than could be accounted for by the difference between the amount calculated on the assumption of simple dilution during growth and observed internal concentrations in the cocci, but the amounts in the supernatant fluid were small and the difference was near the experimental error of the method.

\section{Specificity of thiamine deficiency}

The above observations showed that partial thiamine deficiency in a culture of staphylococci in broth can selectively depress hyaluronidase formation. It was of interest to discover whether this was specific for thiamine or whether cocci partially deficient in other essential growth factors behaved similarly. Nicotinic acid or nicotinamide is another essential growth factor for staphylococci and the influence of deficiency of this factor was examined. For this purpose the organisms were grown on a casein hydrolysate medium (medium $\mathbf{B}$; Rogers, 1945) without added nicotinic acid, and different amounts of nicotinamide added. In another experiment, different amounts of thiamine were added to the medium containing nicotinamide. The media were dispensed in $10 \mathrm{ml}$. amounts in $50 \mathrm{ml}$. conical flasks, and each inoculated with $0.1 \mathrm{ml}$. of a 1/10 dilution of twice-washed cocci prepared from an overnight broth culture of the organisms (i.e. cocci from 5.0 ml. culture were suspended in $50 \mathrm{ml}$. water 
and $0.1 \mathrm{ml}$. taken). The inoculated media were incubated at $35^{\circ}$ with shaking until active hyaluronidase formation had ceased. It will be seen (Table 6) that nicotinic acid deficiency, like shortage of thiamine, selectively suppressed hyaluronidase formation. When sufficient of either factor was present to support half maximum growth hyaluronidase formation was suppressed $70-80 \%$.

\section{Table 6. The suppression of hyaluronidase formation by partial nutritional deficiency}

The basal medium was casein hydrolysate (B) of Rogers (1945) without nicotinic acid and thiamine. For the results under $(a)$ all the flasks contained $1.0 \mu \mathrm{g}$. nicotinamide $/ \mathrm{ml}$.; under $(b)$ all flasks contained $0.02 \mu \mathrm{g}$. thiamine $/ \mathrm{ml}$. All flasks were inoculated with twicewashed cocci from an $18 \mathrm{hr}$. culture to the equivalent of $7 \times 10^{-4} \mathrm{mg}$. bacterial-N. Incubation was for $16 \mathrm{hr}$. at $35^{\circ}$ with shaking.

(a) Variation in the concentration of thiamine

$\begin{array}{ccc}\begin{array}{c}\text { Thiamine } \\ (\mu \mathrm{g} . / \mathrm{ml} .)\end{array} & \begin{array}{c}\text { Mass of } \\ \text { growth (mg. } \\ \text { bacterial-N/ml.) }\end{array} & \begin{array}{c}\text { Hyaluronidase } \\ (\text { TRU } / \mathrm{ml} .)\end{array} \\ 0.02 & 0 \cdot 344 & 90 \\ 0.01 & 0.270 & 39 \\ 0.007 & 0.152 & 15 \\ 0.005 & 0.104 & <2 \\ 0.003 & 0.0835 & <2 \\ 0 & 0.0312 & <2\end{array}$

(b) Variation in the concentration of nicotinamide

$\begin{array}{ccc}\begin{array}{c}\text { Nicotinamide } \\ \text { (ug./ml.) }\end{array} & \begin{array}{c}\text { Mass of } \\ \text { growth (mg. } \\ \text { bacterial-N/ml.) }\end{array} & \begin{array}{c}\text { Hyaluronidase } \\ \text { (TRU/ml.) }\end{array} \\ 1.0 & 0 \cdot 244 & 56 \\ 0.1 & 0 \cdot 182 & 30 \\ 0.05 & 0 \cdot 105 & 12 \\ 0.02 & 0.080 & 2 \\ 0 & 0 \cdot 040 & <1\end{array}$

\section{Suppression of hyaluronidase formation by $\alpha$-aminobutyric acid}

The presence of $\alpha$-aminobutyric acid in cultures of staphylococci was reported by Woiwood \& Proom (1950). This substance has been shown to inhibit the growth of other micro-organisms (Gladstone, 1939; Rowley, 1953; Friedman, 1956). The amino acids liberated from staphylococci by heating suspensions at $100^{\circ}$ for $10 \mathrm{~min}$. (Gale, 1947) were examined by two-dimensional chromatography with phenol/ $\mathrm{NH}_{3}$ and butanol/acetic acid/water as the two solvent mixtures. Three different kinds of washed cocci were examined: (a) cocci, from shaken-flask cultures, which had been multiplying rapidly; (b) cocci from a continuous culture run for $6 \mathrm{hr}$.; (c) cocci from overnight shaken-flask cultures. Approximately the same total amounts of amino acids from each set were applied to the chromatogram. In all three fluids aspartic acid, glutamic acid and alanine predominated. In the extracts from the cocci grown overnight, however, a large spot giving a bright purple colour with ninhydrin appeared in the correct position for $\alpha$-aminobutyric acid. No other 
spots appeared when a mixture of the extract and $\alpha$-aminobutyric acid were chromatographed. Examination of the extracts on copper-impregnated paper (Crumpler \& Dent, 1949) showed that the additional spot given by the extracts from cocci from overnight cultures was not a $\gamma$ amino acid. It was provisionally identified with $\alpha$-aminobutyric acid.

Addition of $\alpha$-aminobutyric acid, but not of $\gamma$-aminobutyric acid, to final concentrations of $0.01 \mathrm{M}$ and $0.005 \mathrm{M}$ to the broth medium gave very variable but significant suppression of the ratio hyaluronidase:mass of growth when cultures were grown from organisms from an overnight culture; the decrease in the ratio of hyaluronidase activity: mass of growth varied from 11 to $50 \%$. No significant inhibition of growth was shown with these concentrations of $\alpha$-aminobutyric acid. The effect has so far proved too variable for detailed study. It seems probable that the selective inhibitory effect of the endogenous $\alpha$-aminobutyric acid may be superimposed upon the selective suppression of enzyme formation by partial thiamine deficiency of the organisms from overnight cultures used to inoculate the cultures.

\section{DISCUSSION}

It has been shown that staphylococci from cultures which have ceased to grow rapidly, when inoculated into fresh medium, secrete an increasing proportion of their protein as hyaluronidase for about eleven generations. Thereafter hyaluronidase forms a constant proportion of the protein synthesized even when the organisms are removed from their growth medium into fresh broth. It is also now known that certain partial nutritional deficiencies can selectively suppress the formation of hyaluronidase and that the inoculum cocci from the overnight culture are deficient in thiamine. Since nicotinamide deficiency causes the same behaviour as thiamine deficiency, it seems unlikely that there is anything specific about the thiamine effect. It may be suggested that any factor which is present in suboptimal amounts will selectively suppress the formation of hyaluronidase. The slow increase in the proportion of hyaluronidase formed during the first eleven generations is not likely to be directly connected with the thiamine deficiency, because when the organisms are placed in fresh medium, they rapidly concentrate thiamine and grow at the expense of this store. If hyaluronidase formation were directly connected with the concentration of thiamine in the organism, the proportion of enzyme formed should rise very rapidly and then fall. If, however, as seems more probable, the amount of hyaluronidase formed is controlled by the concentration within the organism of some other material which depends for its formation on the intervention of diphosphothiamine, then it is easier to understand the very long time required before the maximum amount of enzyme can appear. The substances which control enzyme formation are likely to be required also for the protein formation necessary for growth, and it may require eleven generations before their concentration rises high enough to saturate the hyaluronidase-forming systems.

Superimposed upon the effects of thiamine deficiency is the selective inhibition 
of hyaluronidase by $\alpha$-aminobutyric acid which accumulates in cells from old cultures. Other work (Gladstone, 1939; Friedman, 1956) has shown that the addition to media of certain amino acids (e.g. valine with Bacillus anthracis and alanine + leucine with an Escherichia coli auxotroph which requires isoleucine + valine for optimum growth) can reverse the inhibitory action of $\alpha$-aminobutyric acid. Friedman (1956) suggested that $\alpha$-ketobutyrate derived from the $\alpha$-aminobutyric acid interferes with the biosynthesis of $\alpha$-ketoisovaleric acid, which is a valine and leucine precursor. Therefore, the suppression of hyaluronidase formation by $\alpha$-aminobutyric acid may be another example of selective suppression by partial deficiency of valine or leucine.

A theory suggested by the present work seems to be that some mechanism exists in the cocci for sorting out priorities for constitutive enzyme formation when a deficiency of certain essential growth factors limits protein synthesis. Possibly the formation of some endogenous inducer of hyaluronidase is being altered by this deficiency, but the lack of specificity of the effect argues against such a hypothesis. It seems more probable that there are a series of enzymeforming sites with different requirements for the concentration of intermediates of protein synthesis. The formation of some enzymes may proceed with relatively low available concentrations whereas others may require much higher concentrations.

In conclusion, it may be speculated as to whether a similar situation may not apply in systems where specific 'toxigenic' factors have been fruitlessly sought, such as in the formation of lethal toxin by Clostridium tetani or lecithinase by $C$. welchii.

I should like to thank several colleagues and in particular Dr M. R. Pollock and Dr H. Rickenberg for reading the manuscript of this paper and spending much time discussing aspects of the problem, and Mr I. Mathison for much conscientious technical assistance.

\section{REFERENCES}

Atrin, L., Schultz, A. S. \& Frey, C. N. (1939). Ultra mierodetermination of thiamine by the fermentation method. J. biol. Chem. 129, 471 .

Crumpler, H. R. \& Dent, C. E. (1949). A distinctive test for $\alpha$-amino acids in paper chromatography. Nature, Lond. 164, 441.

Find, R. K. (1954). Agitation-aeration in the laboratory and in industry. Bact. Rev. 18, 254.

Friedman, S. (1956). Studies on the inhibition of growth of Escherichia coli by normal aminobutyric acids. J. Bact. 71, 278.

GaLE, E. F. (1947). The assimilation of amino-acids by bacteria. 1. The passage of certain amino-acids across the cell wall and their concentration in the internal environment of Streptococcus faecalis. J. gen. Microbiol. $1, \mathbf{5 3}$.

Gladstone, G. P. (1939). Inter-relationships between amino acids in the nutrition of B. anthracis. Brit. J. exp. Path. 20, 189.

Kantonowicz, $O$. (1951). Shaking apparatus for the aeration of bacterial cultures. J. gen. Microbiol. $5,276$.

Kuine, O. L. \& Friedman, L. (1947). Microbiological assay methods for thiamin. Biol. Symp. 12, 65.

Monod, J. (1950). La technique de culture: théorie et applications. Ann. Inst. Pasteur, 79, 390. 
Monod, J., Pappenheimer, A. M., Jr. \& Cohen-Bazire, G. (1952). Kinetics of the biosynthesis of $\beta$-galactosidase by $E$. coli considered as a function of growth. Biochim. biophys. Acta, 9, 648.

Novick, A. (1955). Growth of bacteria. Annu. Rev. Microbiol. 9, 97.

RoGERs, H. J. (1945). Conditions controlling the production of hyaluronidase by micro-organisms grown in simplified media. Biochem. J. 39, 435.

Rogers, H. J. (1953). Variant populations within a hyaluronidase producing culture of Staphylococcus aureus. J. Path. Bact. 66, 545.

Rogers, H. J. (1954). The rate of formation of hyaluronidase, coagulase and total extracellular protein by strains of Staphylococcus aureus. J. gen. Microbiol. 10, 209.

Rowley, D. (1953). Interrelationships between amino acids in the growth of coliform organisms. J. gen. Microbiol. 9, 37.

Schultz, A. S., Atkin, L. \& Frey, C. N. (1942). Determinations of Vitamin $B_{1}$ by yeast fermentation. Industr. Engng Chem. (Anal.) 14, 35.

Stamp, LoRd (1947). The preservation of bacteria by drying. J. gen. Microbiol. 1, 251.

Worwood, A. J. \& Proom, H. (1950). Identification of characteristic extracellular ninhydrin-positive substances produced by some bacteria. J. gen. Microbiol. 4, 501.

Wright, H. D. (1933). The importance of adequate reduction of peptone in the preparation of media for the pneumococcus and other organisms. J. Path. Bact. 37, 257.

(Received 27 June 1956) 